\title{
The Principles of Biomedical Scientific Writing: Title
}

\author{
Zahra Bahadoran (iD) ${ }^{1}$, Parvin Mirmiran (iD ${ }^{2}$, Khosrow Kashfi (iD) ${ }^{3}$ and Asghar Ghasemi (iD) ${ }^{4}{ }^{*}$ \\ ${ }^{1}$ Nutrition and Endocrine Research Center, Research Institute for Endocrine Sciences, Shahid Beheshti University of Medical Sciences, Tehran, Iran \\ ${ }^{2}$ Department of Clinical Nutrition and Human Dietetics, National Nutrition and Food Technology Research Institute, Faculty of Nutrition Sciences and Food Technology, \\ Shahid Beheshti University of Medical Sciences, Tehran, Iran \\ ${ }^{3}$ Department of Molecular, Cellular and Biomedical Sciences, Sophie Davis School of Biomedical Education, City University of New York School of Medicine, New York, United \\ States \\ ${ }^{4}$ Endocrine Physiology Research Center, Research Institute for Endocrine Sciences, Shahid Beheshti University of Medical Sciences, Tehran, Iran \\ "Corresponding author: Endocrine Physiology Research Center, Research Institute for Endocrine Sciences, Shahid Beheshti University of Medical Sciences, Tehran, Iran. Email: \\ ghasemi@endocrine.ac.ir
}

Received 2019 September 23; Revised 2019 October 10; Accepted 2019 October 12.

\begin{abstract}
The title of a paper is "like a hat on a head or the front door to a house" and its initial impression. Writing a good and effective title makes the paper more retrievable by search engines and maximizes its impact in the scientific community. The paper's title presents what has been studied, how it has been done, and what are the major results. A well-written title is balanced for being informative and concise, as well as attractively conveying the main topic, highlighting the importance of the study. For writing a good title, it should be drafted correctly, accurately, carefully, and meticulously by the main study keywords. By removing extra and unspecific words, the final title should be unambiguous, memorable, captivating, and informative. Here, we provided an overview of the importance and function of the title as well as different types of titles in scientific medical writing. We also focused on the content and organization of the title of a hypothesis-testing paper. In addition, the features of a good title were discussed.
\end{abstract}

Keywords: Title, Scientific Writing, Biomedical Journals

\section{Context}

The title is the "single most important line of a publication" (1). Although the title is a very small part of a research paper, it plays an important role in connecting the writer with potential readers. It also determines whether the paper is read or not (2). The title of a paper acts as a billboard, a descriptor, an advertisement (3), or a trailer for the movie (4). For every person who reads the whole paper, about 500 people only read the title, indicating that the majority of the papers are read by title alone (5). The title can influence the first impression of the work during the pre-publication process that occurs in the peer-review, as well as the postpublication process, which affects both dissemination and citations $(3,6)$. Therefore, writing an effective title is an important step in scientific writing.

A good title provides a reconciliation between being attractive and being informative (4); it means that the title should motivate the readers to read an article, give them a summary of the contents, and provide an overview of the topics and findings (7). A well-written title will help other researchers to find the paper more easily (8), whereas a poorly written one may make a paper difficult to be retrieved by search engines, discourage readers to go through the text, and reduce an article's impact (9). There are examples where journals have withdrawn a published paper because of it having a wrong title (10), a misleading or an inaccurate title $(11,12)$, or for misuse of words within the title (13).

Following our previous reports on how to write and construct an introduction (14), materials and methods (15), results (16), and discussion (17) as sections of a scientific paper, here, we provided an overview of the importance and function of the title. We also focused on different types of titles that are commonly used in scientific and biomedical writings, in particular highlighting the function, content, and organization of the title in a hypothesis-testing paper.

\section{Functions of the Title}

The title of a biomedical scientific paper has two main functions $(18,19)$ : (1) to present the main topic or the message of the paper (the answer to the question) and (2) to attract potential readers and evoke their interest to read the paper. In fact, the title tells the readers what the paper is all about $(6,19)$. The title also provides some keywords for further search (19) and facilitates the retrieval of the paper from bibliographic databases as this is used by the ab- 
stracting and documentation services in order to classify and index the paper (20).

\section{Content of the Title}

The main elements of a title include intervention, endpoint or outcome, study population, and its specific conditions, design, and setting, which refers to a situation or a place that study was conducted at (21). The main elements in a hypothesis-testing paper, are (1) the independent variable(s) (X), (2) dependent variable(s) (Y), and (3) the study subjects (i.e. animal, population) or materials (i.e. culture media, cell line, tissue) ( $\mathrm{Z}$ ).

If important, the experimental approach and the condition of the animals/subjects during the study can also be included in the title (18). The specific organism or the biological system studied (e.g. animals, bacteria, cell culture) must always be included in the title $(3,18)$. In case of humans, they are often removed from the title $(3,18)$. It means that in biomedical journals, it is assumed that the species studied is human unless otherwise stated (3) and no population in the title indicates that the population is humans (18). However, if a subpopulation of humans was studied (e.g. patients who have asthma), that should be included in the title (18). Indication of the study setting (e.g. community-based, home-based, school-based, hospital-based, rural or urban setting) in the title is only important if the results are not generalizable to other settings, or if the setting reflects the magnitude of the research (21).

In descriptive papers, where a new structure is described, an important element of the title is to name that structure and its key function (18). In method papers, the name of the method (apparatus or material), its purpose, and the population where the method is used for are key elements of the title (18). According to the journal's style or where appropriate, the study design may also be stated (8). This is especially true for randomized clinical trials, cohort, case-control, and cross-sectional studies (4). What this does is to alert the readers regarding the level of the evidence in the paper (4). Stating the study design in the title, usually located after a colon or an Em dash, makes the title more complete (21). Stating what type the review is (narrative, systematic or quantitative systematic) may also be helpful, especially for quantitative systematic reviews (meta-analysis) where a high level of evidence is suggested (4).

\section{Organization of the Title}

\subsection{Descriptive (Neutral) Titles}

Descriptive titles describe the subject of the paper but do not reveal the main conclusions (22) and are usually rec- ommended as the best form of titles (23). Most of these contain all the elements of the research work (e.g. study population, intervention, study outcome, comparison)(21, 23). In a hypothesis-testing paper, a descriptive title traditionally states the topic of the paper using its three essential pieces of information (dependent variable, independent variable, study subject or material), the so-called $\mathrm{X}, \mathrm{Y}$, and $Z$ (18); e.g. a common form of such titles are "effect of $\mathrm{X}$ on Y in Z" (e.g. Effect of broccoli sprouts on insulin resistance in type 2 diabetic patients: a randomized doubleblind clinical trial (24)) or "Y during X in Z" (e.g. change of maternal serum triglycerides during third trimester of pregnancy in obese women). Usually, Z comes at the end of the title (18). Where there is no independent variable (X), the title would be $\mathrm{Y}$ in $\mathrm{Z}$ (e.g. dynamics of the chest wall in preterm infants) (18). If the study has several independent or dependent variables where they cannot be summarized under the general categories, it is advisable to select the most important ones (18) since these are new findings and should be presented in the title (25).

\subsection{Declarative Titles}

Declarative titles present the main conclusions or the actual message of the study $(26,27)$. The message can be stated in a phrase or in a sentence (18). When the message is expressed in a phrase, an adjective or a noun (based on the verb used in the question and answer) or a combination of both are placed at the beginning of the title before the dependent variable; e.g. "reduced metabolic rate during radio-frequency irradiation in rats", in which the message is expressed as an adjective, reduced (18). When the message is expressed in a sentence, a verb in the present tense is used; e.g. continuous positive airway pressure impairs renal function in anesthetized newborn goats (18). Using a sentence is stronger than using a phrase (because verbs convey an action more powerful than adjectives and nouns); therefore, it is used only when solid evidence supports a clear message (18). Some believe that using a sentence as a title overemphasize a conclusion and is best to be avoided (4).

In hypothesis-testing papers, the message of the paper can be stated in the title, where the message is strong and clear, and is supported by strong and solid evidence $(18,23)$. Authors also need to be ensured that the title is true and is supported by the rest of the paper (28). When the title is a complete sentence, it conveys the impression that the study has reached a definite conclusion (19). e.g. "endothelium-derived relaxing factor produced and released from artery and vein is nitric oxide" (29).

Some believe that declarative titles would help authors to select a more appropriate paper during their search (27). For some types of papers such as commentaries, journals (e.g. obstetrics and gynecology) may push the authors to 
write a declarative title regarding the commentary's main argument(s). Declarative titles give the impression that the findings of the study have general validity, which rarely is the case (26). Editors are, therefore, more cautious in accepting declarative titles due to its possible impact on public health (22) and some journals do not accept declarative titles (e.g. New England Journal of Medicine) (26). In addition, in case of choosing a declarative title, authors need to ask themselves will the title kill the curiosity? Will the readers lose motivation and interest to read the full article? (23).

Generally, the present tense in the title emphasizes the general validity of the results whereas the past tense indicates that the results are not established knowledge yet. To state results of a single investigation past tense and for results of a systematic review present tense should be used (27).

\subsection{Interrogative Titles}

To make a title more attractive, an interrogative form, which phrases the subject of the paper in the form of a question, can be used (30). However, in hypothesis-testing papers, interrogative titles are not recommended (31), because the reader would appreciate being told the answer from the beginning (30). An interrogative title may be appropriate for a review article, where the controversial issues are being discussed in response to the study question (30); e.g. are shorter article titles more attractive for citations? Cross-sectional study of 22 scientific journals (32). Interrogative titles in general lead to more paper downloads but may result in fewer citations (22).

\subsection{Compound Titles}

Compound titles (or hanging titles) contain the main title and a subtitle (23) that are separated by a colon (:) (18). Compound titles can be started with a short question, a subject sentence, or a noun phrase, followed by a colon and a declarative sentence or a question (22). These types of titles are used to provide additional relevant information (e.g. about the study design, geographic or temporal scope of the research) or to add substance to a provocative area (23); e.g. developmental origins of type 2 diabetes: focus on epigenetics (33). They are useful for complex studies (19) and series papers (18). Using subtitles is not recommended except for putting an important word first (18). Papers with subtitles seem to be more attractive and are less likely to be rejected (34). In a compound title, the main part (main title) should be standalone (4).

\subsection{Other Types of Title}

Other styles, less commonly used to organize the title, are "indicating the direction of the author's opinion", "em- phasizing the methodology used in the research", "suggesting guidelines", or "making a comparison" (35). To get more attention, the use of "effective opening", "alliteration", "irony", "puns", "humor" or "mystifying” (35) may also be used. However, the latter styles do help the paper grab readers' attention, the authors need to ensure they will be understood and appreciated by all readers and are culturally appropriate (23). One example of referring to a parable in the title is: challenges for measuring oxytocin: the blind men and the elephant? (36), in which the subtitle refers to the parable of the 6 blind men and the elephant.

\section{The Procedure of Writing an Effective Title}

Although it is the first section of a paper that is seen (3, $6,19)$, title is drawn from other sections of paper (3) and the final title is usually written as the last part (19). Good titles are created with care and craft (4). Writing a good title needs a back-and-forth process by continuous going back to the text with a sharper focus on what the paper is trying to say (35).

As shown in Figure 1, a stepwise process is suggested to be followed to draft a title. What the authors need to do in the first step is to consider the manuscript entirely and then try to describe the content of the paper using essential keywords and phrases. Then, they need to make a sentence by the selected keywords and then remove redundant and nonspecific words/adjectives (20). The keywords used in the title should be the same as that used in the question and answer in the introduction, discussion, and abstract (18). The initial title must then be reviewed, refined and finally checked for having features of an effective final title. The title should not be hastily finalized; making a consultation with colleagues to get their opinion and possible suggestions can help improve the title (23). The authors are highly recommended to adhere to the style of the journal that they are submitting to e.g. word count, other instructions such as acceptable types of title (declarative and interrogative ones are unacceptable by some), use of capital letters, hyphens, colon, etc.

\section{Features of a Suitable Title}

In addition to highlighting the subject matter (be informative), the title of the paper should be eye-catching (be attractive) $(25,37)$. The most important concept should be placed at or near the beginning of the title (where it most readily catches the reader's eye) (25). Table 1 describes the features of a good title. In brief, a well-written title should be attractive and engaging $(4,6,26)$, comprehensive $(8,37)$, accurate (18), sufficiently descriptive (37), complete (18), informative $(3,4,6,8)$, and specific $(4,18,37)$ as well as be con- 


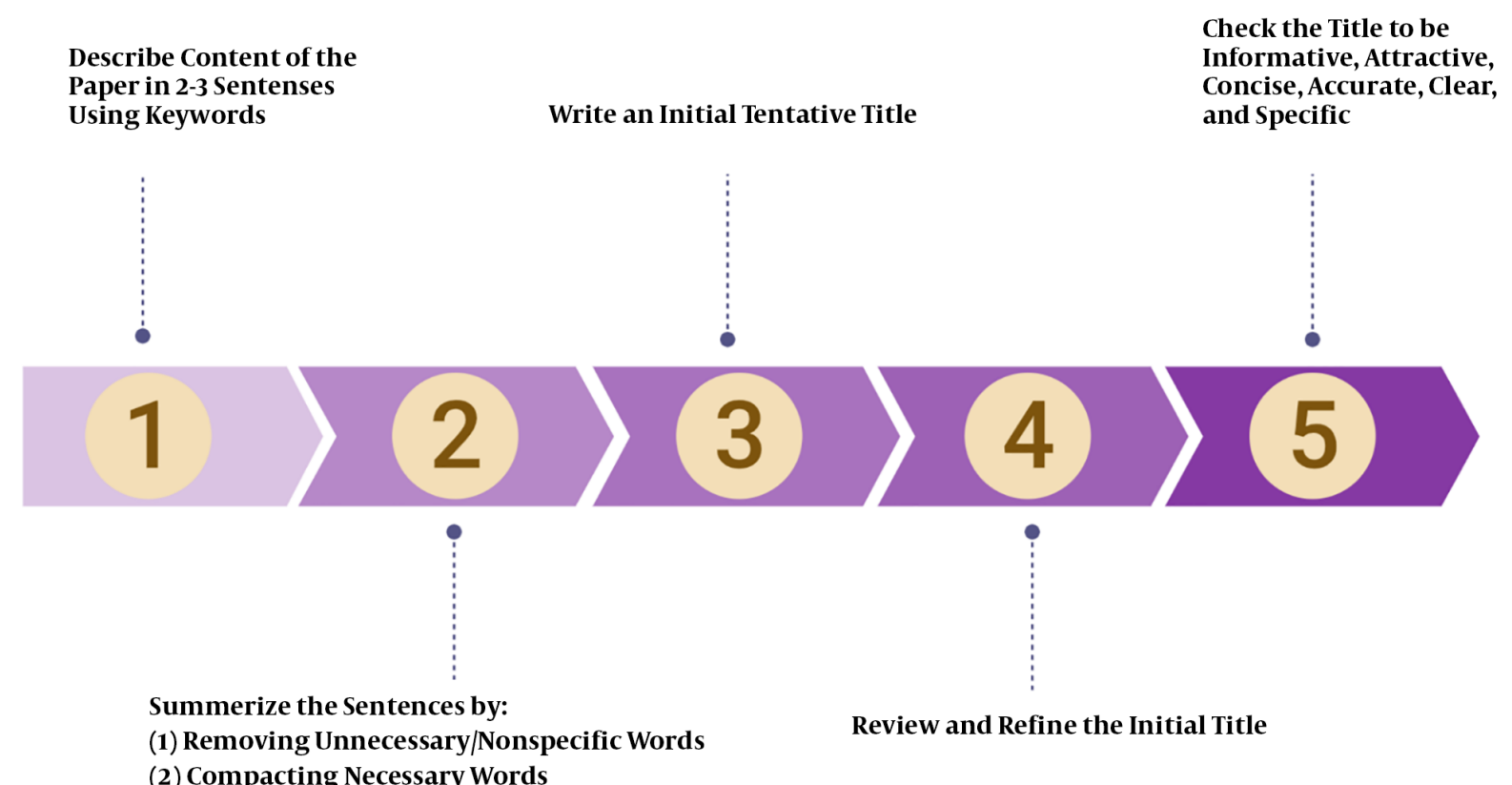

Figure 1. A five-step process of writing a title for a research paper is depicted. Created using BioRender.com.

cise $(3,4,6,8,18,26,37)$, clear (unambiguous) $(3,18)$ and begins with an important term $(3,18)$. The title should not be too general $(19,31)$ or too-detailed (31), be misleading or unrepresentative (26), omit major elements (19), or include unnecessary details (19).

\section{Length of the Title}

Although longer titles may provide more information regarding the content, they reduce the interest generated (39). A short title is easier to understand and can attract a wider readership and increase the influence of the paper (40). Therefore, the authors are advised to make the title as short as possible without sacrificing accuracy, completeness, specificity, and clarity (18). High-impact journals usually restrict the length of their papers' titles (40).

Try to keep your title shorter than 100 characters (i.e. letters and punctuation marks), including spaces (120 characters are considered the upper limit) (18). As the rule of thumb, 10 - 12 words may be the ideal length of a paper (41) and the title should not be more than 12 words (31).

\section{Word Choice in the Title}

In addition to being relevant to the target audience (3), every word (excluding articles e.g. the, a, an, and preposi- tions e.g. to, about, on) used in the title should add significance (28). Words in the title need to be checked by Medical Subjects Headings (MeSH) (31). Using study keywords to formulate a title is highly recommended. Using the most important keywords in the title is essential for appropriate indexing purposes and for retrieval by search engines and available databases (38). Indexing services (e.g. PubMed) and search engines (e.g. Google) use keywords and terms in the title $(3,6)$. Titles should not start with a numeral, or expressions like "a study of", "a contribution to", "investigations on" or "some interesting" (20). "Influence of" does not evoke much curiosity and if possible should be avoided (25).

Generally, the use of neutral words (e.g. inquiry, analysis, evaluation, assessment, etc.), that give no information to the readers, is not recommended (28). However, in some cases, these words may be necessary to inform the scope, intent, or type of a study (42). Although the use of catchy phrases or non-specific language is not recommended in academic writing, they can be used within the context of the study (42).

Adjectives (e.g. increased) that modify quantitative words (e.g. metabolic rate) are different from those (e.g. improved) that modify qualitative words (e.g. performance) (18). Some adjectives such as "novel" or "innovative" need to be replaced by more explicit adjectives to ex- 


\begin{tabular}{|c|c|}
\hline Features & How to Be \\
\hline \multirow{3}{*}{ Being informative $(3,38)$} & Present essential and enough information about the study \\
\hline & Use study keywords and key terms \\
\hline & Inform readers about independent variable, dependent variable, observed effects, and study population \\
\hline Being accurate (18) & Provide the content or state the message as that used within the text \\
\hline \multirow{4}{*}{ Being specific $(8,18,21)$} & $\begin{array}{l}\text { Use specific instead of general words or phrases to make the paper more retrievable (e.g. state the type of } \\
\text { education instead of stating it alone when the paper is about nurse education) }\end{array}$ \\
\hline & $\begin{array}{l}\text { Provide important details (e.g. vitamin D and pneumonia vs. vitamin D deficiency and risk for severe } \\
\text { pneumonia in children under-five) }\end{array}$ \\
\hline & Do not use unspecific words (e.g. and, with) as much as possible \\
\hline & $\begin{array}{l}\text { Use "and" correctly (e.g. to join two parallel terms instead of joining the independent and the dependent } \\
\text { variables) }\end{array}$ \\
\hline \multirow{6}{*}{ Being concise (18) } & Omit unnecessary words \\
\hline & Omit "the" at the beginning of the title (not before singular nouns later in the title) \\
\hline & Do not use unspecific words such as "a study of", "investigation of" or "observation on" \\
\hline & Do not use phrases like "role of", "effect of", and "treatment of" \\
\hline & Do not use some adjectives such as "new", "improved”, "novel”, "validated", and “sensitive" \\
\hline & $\begin{array}{l}\text { Compact necessary words using category terms, adjective instead of noun (e.g. "reduced" instead of } \\
\text { "reduction in"), and noun clusters }\end{array}$ \\
\hline Being unambiguous (clear) $(3,6,18,26,37)$ & Do not use noun cluster, abbreviation, and jargon \\
\hline
\end{tabular}

plain to the readers what makes the study novel (28); e.g. "A noninvasive method of predicting pulmonary-capillary wedge pressure" (43) or "An ultrasound method for safe and rapid central venous access" (44). If possible, replace long words with short ones (26). Try to avoid gerunds (verb forms that end in -ing) in the title as the actor is obscured (31). Avoid using generic terms such as animal, bacteria, or antibiotic as key terms (3).

Abbreviations confuse readers and usually are not used by indexing services (3). In some situations, e.g. long or technical terms in scientific writings, the use of abbreviations can be useful (21). Using abbreviations that appear as word entries in Webster's Collegiate Dictionary (21), are better known than their words (e.g. DNA, AIDS, and FDA) (3, 18 ), or abbreviations for chemicals (e.g. $\mathrm{N}_{2} \mathrm{O}_{5}$ ), are acceptable in the title (18).

\section{Word Order in the Title}

Paying attention to syntax (word order) in the title is important because it can influence the reader's interest in the paper (3). Generally, words at the beginning of the title make the most impact (20). Put an important word (e.g. independent or dependent variables) first in the title to attract readers $(3,18,25,26)$. What you want to be emphasized as the primary subject matter i.e. the key concept of the paper needs to appear first and near the beginning of the title $(3,25)$. Because search engines such as Google, typically show only the first 6 - 7 words of a title, most associated terms should, therefore, appear earlier (3). Using a subtitle (to state-specific topic) following the main title (to state general topic) is a technique for putting an important word or phrase first in the title (18); e.g. "Holistic review: shaping the medical profession one applicant at a time" (45) or "Medical school admissions: applicant projections revisited" (46).

\section{Use of Preposition in the Title}

A preposition is a word or a group of words used before a noun, pronoun, or noun phrase to show direction, time, place, location, spatial relationships, or to introduce an object. Correct use of prepositions in the title makes it more clear and helps the reader to understand how the title elements are related to each other (28). Typical prepositions used in the title, are by (to indicate how something is done), for (referring to a purpose), from (referring to the origin of something), in (referring to a location), of (belonging to or regrading) (28).

\section{Running Title}

To identify the articles in a journal, short phrases called running titles (running heads) appear at the top or bottom 
of every page or every other page $(6,18)$. Running titles are short versions of the title $(6,18)$ and help readers to keep track of the article throughout its printed pages (21). As running titles mostly cannot be longer than 50 characters (including the spaces), authors are recommended to use standard abbreviations and omit the study design (21). In hypothesis-testing papers, the running title usually names independent and dependent variables (18). The form " $\mathrm{X}$ and Y", which is unspecific for the title can be used for the running title (18).

\section{Title and Paper Citation}

A well-organized title is positively associated with paper citation (47). Some studies have addressed how the feature and structure of a title can affect pre- and postpublication manuscript success (9). Association of title's length and citation of the paper has remained inconclusive $(47,48)$, however, papers with shorter titles (40) especially when presenting study conclusion (49) receive more citations (40). Analysis of published papers in the Lancet journal showed that titles with two components separated by a colon were significantly more common in the wellcited papers (47). Titles emphasizing broader conceptual or comparative issues get more attention than those being more specific (e.g. use of particular genus or species by their taxonomic name in the title)(9). Some factors such as referring to a specific country or geographical region may also lead to poor citation of the paper $(47,49)$. Other factors such as punctuations and use of acronyms can also affect the citation rate of a paper (47). Use of "colon", "hyphen" and "comma" was most frequent whereas "semi-colon", "dash" and "single quotation marks" were least frequent punctuation marks in top-cited papers (50).

\section{Conclusions}

The essence of research is reflected in its title, which acts as a "signpost" for the main topic of the paper (31). In addition to presenting the message of the paper, the title should evoke interest in reading the paper. Appropriate types of a title (e.g. descriptive, declarative, interrogative) should be selected by the authors and in all cases, the title should be accurate, unambiguous, interesting, concise, precise, unique, and should not be misleading. "The Title" should present the substance of the work in a clear way.

\section{Footnotes}

Authors' Contribution: Study concept and design: Zahra Bahadoran and Asghar Ghasemi; drafting of the manuscript: Zahra Bahadoran, Parvin Mirmiran, and Asghar Ghasemi; critical revision of the manuscript for important intellectual content: Khosrow Kashfi and Parvin Mirmiran.

Conflict of Interests: The authors have no conflict of interest.

Funding/Support: This study was supported by the Research Institute for Endocrine Sciences, Shahid Beheshti University of Medical Sciences.

\section{References}

1. Langford CA, Pearce PF. Increasing visibility for your work: The importance of a well-written title.JAm Assoc Nurse Pract. 2019;31(4):217-8. doi:10.1097/JXX.0000000000000212. [PubMed: 30964827].

2. Haggan M. Research paper titles in literature, linguistics and science: Dimensions of attraction. J Pragmat. 2004;36(2):293-317. doi: 10.1016/s0378-2166(03)00090-0.

3. Annesley TM. The title says it all. Clin Chem. 2010;56(3):357-60. doi: 10.1373/clinchem.2009.141523. [PubMed: 20044445].

4. Anstey A. Writing style: What's in a title? $\mathrm{Br} J$ Dermatol. 2014;170(5):1003-4. doi: 10.1111/bjd.13039. [PubMed: 24841579].

5. Kerkut GA. Choosing a title for a paper. Comp Biochem Physiol A Physiol. 1983;74(1):1. doi: 10.1016/0300-9629(83)90702-8.

6. Peh WC, Ng KH. Title and title page. Singapore Med J. 2008;49(8):607-8. quiz 609. [PubMed: 18756341].

7. Ball R. Scholarly communication in transition: The use of question marks in the titles of scientific articles in medicine, life sciences and physics 1966-2005. Scientometrics. 2009;79(3):667-79. doi: 10.1007/s11192-007-1984-5.

8. Grant MJ. What makes a good title? Health Info Libr J. 2013;30(4):25960. doi: 10.1111/hir.12049. [PubMed: 24251888].

9. Fox CW, Burns CS. The relationship between manuscript title structure and success: Editorial decisions and citation performance for an ecological journal. Ecol Evol. 2015;5(10):1970-80. doi: 10.1002/ece3.1480. [PubMed: 26045949]. [PubMed Central: PMC4449752].

10. Moore N. Journal's withdrawal of article. Paper OK, title wrong. BMJ. 2011;342:d2732. doi: 10.1136/bmj.d2732. [PubMed: 21558338].

11. Cohen DA. Misleading title of review paper. EurJClin Invest. 2019;49(5). e13081. doi: 10.1111/eci.13081. [PubMed: 30725493].

12. Koninckx PR, Ussia A, Donnez J, Stepanian A, Adamyan L, Wattiez A. The title is misleading: An opinion paper is not a consensus paper. Hum Reprod. 2013;28(11):3161. doi: 10.1093/humrep/det281. [PubMed: 23851221].

13. Wenban $\mathrm{AB}$. Inappropriate use of the title 'chiropractor' and term 'chiropractic manipulation' in the peer-reviewed biomedical literature. Chiropr Osteopat. 2006;14:16. doi: 10.1186/1746-1340-14-16. [PubMed: 16925822]. [PubMed Central: PMC1570468].

14. Bahadoran Z, Jeddi S, Mirmiran P, Ghasemi A. The principles of biomedical scientific writing: Introduction. Int J Endocrinol Metab. 2018;16(4). e84795. doi: 10.5812/ijem.84795. [PubMed: 30464776]. [PubMed Central: PMC6218661].

15. Ghasemi A, Bahadoran Z, Zadeh-Vakili A, Montazeri SA, Hosseinpanah F. The principles of biomedical scientific writing: Materials and methods. Int J Endocrinol Metab. 2019;17(1). e88155. doi: 10.5812/ijem.88155. [PubMed: 30881471]. [PubMed Central: PMC6413392].

16. Bahadoran Z, Mirmiran P, Zadeh-Vakili A, Hosseinpanah F, Ghasemi A. The principles of biomedical scientific writing: Results. Int J Endocrinol Metab. 2019;17(2). e92113. doi: 10.5812/ijem.92113. [PubMed: 31372173]. [PubMed Central: PMC6635678].

17. Ghasemi A, Bahadoran Z, Mirmiran P, Hosseinpanah F, Shiva N, ZadehVakili A. The Principles of Biomedical Scientific Writing: Discus- 
sion. Int J Endocrinol Metab. 2019;17(3). e95415. doi: 10.5812/ijem.95415 [PubMed: 31497043]. [PubMed Central: PMC6679622].

18. Zeiger M. Essentials of writing biomedical research papers. McGraw-Hill; 2000.

19. Morgan PP, Baker G. Writing the right title. Can Med Assoc J. 1984;131(10):1180. [PubMed: 20314465]. [PubMed Central: PMC1483692].

20. Manten AA, Greenhalgh JFD. Titles of scientific papers. Anim. Feed Sci Technol. 1977;2(1):1-6. doi:10.1016/0377-8401(77)90035-9.

21. Dewan P, Gupta P. Writing the title, abstract and introduction: Looks matter!. Indian Pediatr. 2016;53(3):235-41. doi: 10.1007/s13312-016-0827y. [PubMed: 27029687]

22. Jamali HR, Nikzad M. Article title type and its relation with the number of downloads and citations. Scientometrics. 2011;88(2):653-61. doi 10.1007/s11192-011-0412-z.

23. Bavdekar SB. Formulating the right title for a research article. J Assoc Physicians India. 2016;64(2):53-6. [PubMed: 27730781]

24. Bahadoran Z, Tohidi M, Nazeri P, Mehran M, Azizi F, Mirmiran P. Effect of broccoli sprouts on insulin resistance in type 2 diabetic patients: A randomized double-blind clinical trial. Int J Food Sci Nutr. 2012;63(7):767-71. doi: 10.3109/09637486.2012.665043. [PubMed: 22537070].

25. Moore A. What's in a title? A two-step approach to optimisation for man and machine: writing good titles is a crucial part of optimising articles' chances of being peer reviewed, and later found in the literature via Google: Here are some tips. Bioessays. 2010;32(3):183-4. doi: 10.1002/bies.201090009. [PubMed: 20162661].

26. Gjersvik P. This is a good title. Tidsskr Nor Laegeforen. 2013;133(2):129. doi: 10.4045/tidsskr.12.1527. [PubMed: 23344583].

27. McGowan J, Tugwell P. Informative titles described article content. J Can Health Libr Assoc. 2005;26(3):83-4. doi: 10.5596/c05-029.

28. Wallwork A. Title, in English for writing research papers. Springer; 2016. doi:10.1007/978-3-319-26094-5_12.

29. Ignarro LJ, Buga GM, Wood KS, Byrns RE, Chaudhuri G. Endotheliumderived relaxing factor produced and released from artery and vein is nitric oxide. Proc Natl Acad Sci U S A. 1987;84(24):9265-9. doi: 10.1073/pnas.84.24.9265. [PubMed: 2827174]. [PubMed Central: PMC299734]

30. Gustavii B. Title, in How to write and illustrate a scientific paper. Cambridge University Press; 2008. doi: 10.1017/cbo9780511808272.010.

31. Hays JC. Eight recommendations for writing titles of scientific manuscripts. Public Health Nurs. 2010;27(2):101-3. doi: 10.1111/j.1525 1446.2010.00832.x. [PubMed: 20433663].

32. Habibzadeh F, Yadollahie M. Are shorter article titles more attractive for citations? Cross-sectional study of 22 scientific journals. Croat Med J. 2010;51(2):165-70. doi: 10.3325/cmj.2010.51.165. [PubMed: 20401960]. [PubMed Central: PMC2859422].

33. Vaiserman A, Lushchak O. Developmental origins of type 2 diabetes: Focus on epigenetics. Ageing Res Rev. 2019;55:100957. doi: 10.1016/j.arr.2019.100957. [PubMed: 31473332].

34. Villar RR. Citations-be sure to have a good title. J Hip Preserv Surg. 2017;4(2):119-20. doi: 10.1093/jhps/hnx025. [PubMed: 28630732]. [PubMed Central: PMC5467414].

35. Hartley J. There's more to the title than meets the eye: Explor- ing the possibilities. J Tech Writing Commun. 2016;37(1):95-101. doi: 10.2190/bj16-8385-7q73-1162.

36. MacLean EL, Wilson SR, Martin WL, Davis JM, Nazarloo HP, Carter CS. Challenges for measuring oxytocin: The blind men and the elephant? Psychoneuroendocrinology. 2019;107:225-31. doi: 10.1016/j.psyneuen.2019.05.018. [PubMed: 31163380]. [PubMed Central: PMC6634994].

37. Cuschieri S, Grech V, Savona-Ventura C. WASP (write a scientific paper): Structuring a scientific paper. Early Hum Dev. 2019;128:114-7. doi: 10.1016/j.earlhumdev.2018.09.011. [PubMed:30236948].

38. Tullu MS. Writing the title and abstract for a research paper: Being concise, precise, and meticulous is the key. Saudi I Anaesth. 2019;13(Suppl 1):S12-7. doi: 10.4103/sja.SJA_685_18. [PubMed: 30930712]. [PubMed Central: PMC6398294].

39. Hudson J. An analysis of the titles of papers submitted to the UK REF in 2014: Authors, disciplines, and stylistic details. Scientometrics. 2016;109(2):871-89. doi: 10.1007/s11192-016-2081-4. [PubMed: 27795594]. [PubMed Central: PMC5065898].

40. Letchford A, Moat HS, Preis T. The advantage of short paper titles. $R$ Soc Open Sci. 2015;2(8):150266. doi: 10.1098/rsos.150266. [PubMed: 26361556]. [PubMed Central: PMC4555861].

41. Schofield SJ, Schofield PG. What's in a name? Word inflation, punctuation, abbreviation and cloud formation. Med Educ. 2016;50(12):1264-8. doi: 10.1111/medu.13099. [PubMed: 27873412].

42. University of Southern California. Organizing your social sciences research paper: Choosing a title. General reference \& research help. 2019. Available from: https://libguides.usc.edu/writingguide/title.

43. McIntyre KM, Vita JA, Lambrew CT, Freeman J, Loscalzo J. A noninvasive method of predicting pulmonary-capillary wedge pressure. $N$ Engl J Med. 1992;327(24):1715-20. doi: 10.1056/NEJM199212103272404. [PubMed: 1435916].

44. Denys BG, Uretsky BF, Reddy PS, Ruffner RJ, Sandhu JS, Breishlatt WM. An ultrasound method for safe and rapid central venous access. NEngl J Med. 1991;324(8):566. doi: 10.1056/NEJM199102213240816. [PubMed: 1992315].

45. Witzburg RA, Sondheimer HM. Holistic review-shaping the medical profession one applicant at a time. $N$ Engl J Med. 2013;368(17):1565-7. doi: 10.1056/NEJMp1300411. [PubMed: 23574032].

46. McRae DJ. Medical school admissions: Applicant projections revisited. J Med Educ. 1978;53(7):612-4. doi: 10.1097/00001888-19780700000018. [PubMed: 671512].

47. Jacques TS, Sebire NJ. The impact of article titles on citation hits: an analysis of general and specialist medical journals. JRSM Short Rep. 2010;1(1):2. doi: 10.1258/shorts.2009.100020. [PubMed: 21103094]. [PubMed Central: PMC2984326].

48. Bramoullé Y, Ductor L. Title length.JEcon Behav Organ. 2018;150:311-24. doi:10.1016/j.jebo.2018.01.014.

49. Paiva CE, Lima JP, Paiva BS. Articles with short titles describing the results are cited more often. Clinics (Sao Paulo). 2012;67(5):509-13. doi: 10.6061/clinics/2012(05)17. [PubMed: 22666797]. [PubMed Central: PMC3351256].

50. Falahati Qadimi Fumani MR, Goltaji M, Parto P. The impact of title length and punctuation marks on article citations. Ann Libr Inf Stud. 2015;62(3):126-32. 